\title{
Technical School News
}

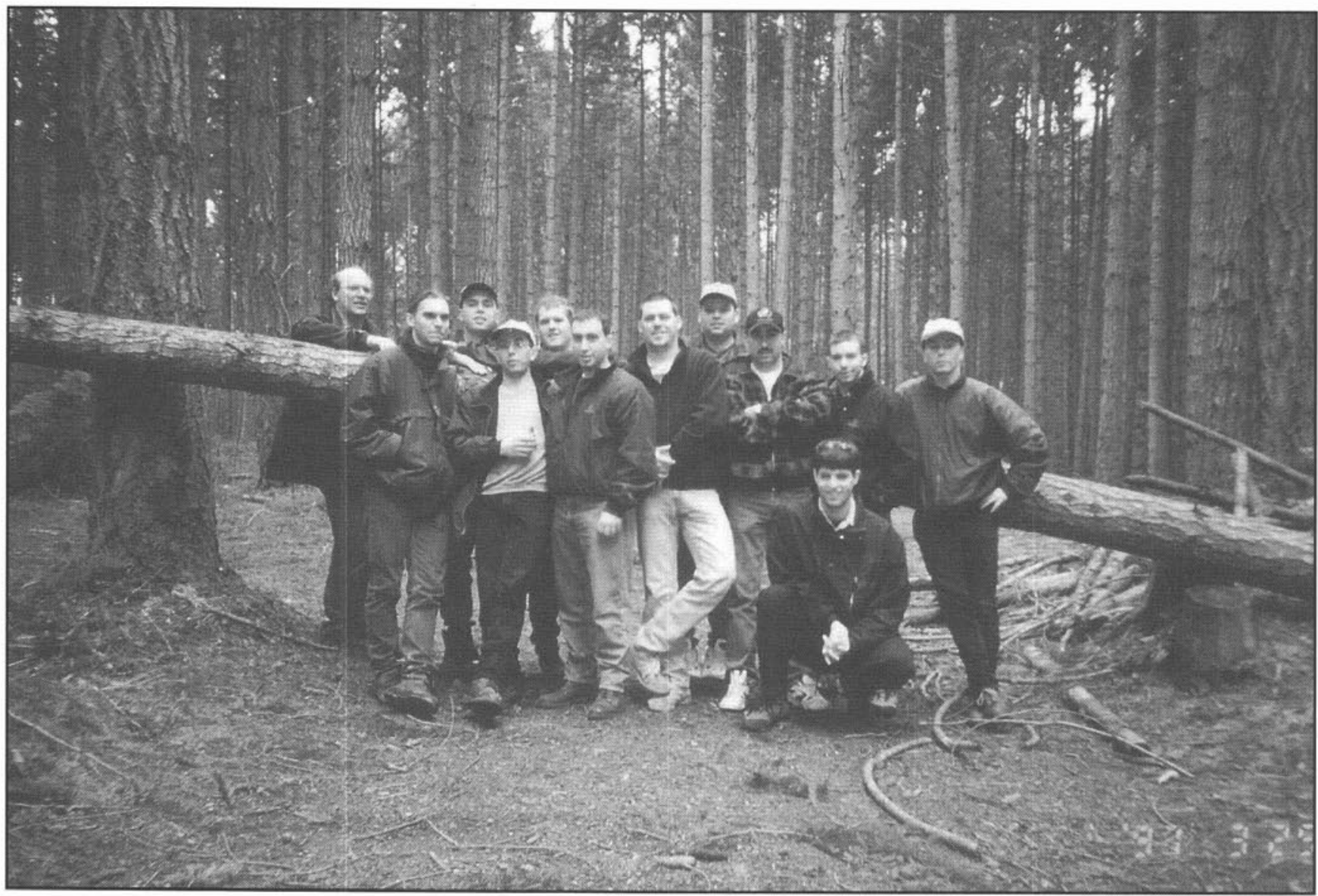

\section{Cegep de la Gaspésie et des lles}

The third year students have achieved their goal which was to visit British Columbia as their in-service period for their silviculture course. After having raised money by organizing activities for the past year and half, they flew to BC last March for a 10 day stay. They visited several interesting sites on Vancouver Island, thanks to Mr. Dave Clark from MacMillanBloedel. In Tofino, they viewed an old growth stand on Meares Island with their guide, Mrs. Chander Wong and had a presentation on the Model Forest Network at the Rain Forest Interpretive Center.
Students then had a guided tour of the Seamour Watershed project, thanks to $\mathrm{Mr}$. Don Campbell of the British Columbia Institute of Technology. The students ended their trip by travelling to the Banff area where they could contemplate the landscape of the Rockies and Lake Louise, returning through the Okanagan Valley. The students were very impressed by the size of trees and species composition which is so different from that back in the east. They were enchanted by their trip and strongly recommend the experience to other students because it is well worth the effort. The teacher who accompanied the students, Mr. Yvan Gagnon, ing.f., would also relive the experience anytime. Yvan believes that such an exchange between technical schools should be encouraged because it is very constructive for the students as well as the school.

Lucie Thibodeau, ing.f., M.Sc. Professor, Department of Forest Technology

Cégep de la Gaspésie et des Iles

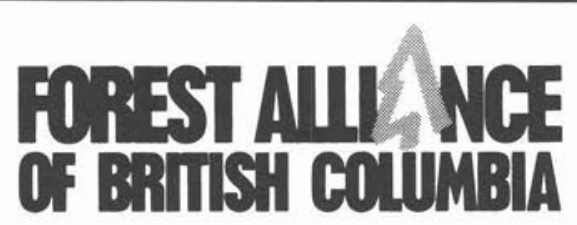

A CIF/IFC Corporate Sustaining Member 